\title{
Groundwater Quality in Western China: Challenges and Paths Forward for Groundwater Quality Research in Western China
}

\author{
Peiyue $\mathrm{Li}^{1,2}$ (1)
}

Received: 2 May 2016/Accepted: 2 May 2016/Published online: 9 August 2016

(C) Springer Science+Business Media Dordrecht 2016

\begin{abstract}
Groundwater quality issues are becoming as important as groundwater quantity issues, making groundwater quality research a hot topic worldwide. With human activity intensifying in western China as a result of the West Development Program and the Silk Road economic belt project of China, groundwater quality in western China is deteriorating rapidly. This special issue of Exposure and Health promotes groundwater quality research to respond to these challenges. This introductory article details the challenges faced by contemporary groundwater quality researchers, and proposes ways to advance groundwater quality research in western China. The paper also introduces the articles that follow in this special issue. The key goal of this work is to encourage new and experienced scholars to engage with this field.
\end{abstract}

Keywords Groundwater pollution · Groundwater quality · Health risk · Hydrochemistry - Water quality assessment . Western China

Peiyue Li

lipy2@163.com; peiyueli@chd.edu.cn

1 School of Environmental Science and Engineering, Chang' an University, No. 126 Yanta Road, Xi'an 710054, Shaanxi, China

2 Key Laboratory of Subsurface Hydrology and Ecological Effects in Arid Region of the Ministry of Education, Chang' an University, No. 126 Yanta Road, Xi' an 710054, Shaanxi, China

\section{Introduction}

Groundwater is the most important water resource in western China, because precipitation and surface water is so limited (Li et al. 2014a; Wang et al. 2007). The West Development Program of China motivated rapid urbanization and industrialization in western China, inducing serious groundwater pollution. Concerns about groundwater quality issues have grown (Rebolledo et al. 2016), and many consider these problems to be among the most important environmental, social, and political issues at global and national levels (Azizullah et al. 2011; Nickson et al. 2005). Groundwater can harm humans through drinking and dermal contact exposure pathways (Bhutiani et al. 2016; Chidambaram et al. 2015; Wu and Sun 2015). As a result of both natural factors and human activities, it is estimated that $18 \%$ of the groundwater in western China is of such poor quality that it cannot be directly used for multiple purposes (China Groundwater Information Web 2016).

The Silk Road project will introduce more industries into western China, potentially increasing water resource and environmental health challenges (Li et al. 2015). Many water resource investigations and geological surveys have been planned to support the Silk Road project, and some research institutes have been established. Researchers are also exploring the contradiction between economic growth and environmental protection (e.g., Chen et al. 2016a; Li et al. 2016a; Mamat et al. 2016; Peng et al. 2016; Xie et al. 2015). These studies are one small step toward the sustainable development of society and the environment. Additional in-depth and comprehensive research, particularly in the field of groundwater quality protection and management, is needed.

Those involved in groundwater quality protection and management face unprecedented challenges because of 
intense human activities and significant natural environmental changes. Together, these two dominant forces are responsible for groundwater quality variability $(\mathrm{Li} 2014)$. Further, they are inextricably intertwined, complicating groundwater quality research. Efficient and effective groundwater quality protection and management require a more comprehensive and efficient scientific and societally informed research framework, a more rational knowledge structure, and a larger group of experienced research hydrogeologists (Li 2016).

We must, however, first understand the challenges so that hydrogeologists are better prepared to face them. Therefore, this introductory article (1) discusses the challenges faced in contemporary groundwater quality research, (2) proposes methods for developing efficient groundwater quality research in western China, and (3) briefly introduces the articles in this special issue. The goal is to encourage Chinese and international scholars to continue their groundwater quality research in western China.

\section{Challenges}

\section{Groundwater Quality Research is Becoming More Complicated}

Groundwater systems are very complex, involving diverse hydrogeological conditions, various formation mechanisms, and different influencing factors. All must be comprehensively considered in groundwater quality research. In addition, human activities impact the groundwater quality in a variety of ways, making groundwater quality research more complex. For example, the Weining Plain in northwest China is experiencing groundwater circulation changes due to long-term agricultural irrigation and groundwater extraction ( $\mathrm{Li} 2014$ ), groundwater quality deterioration because of industrialization and urbanization (Li et al. 2016b, c), and secondary soil salinization due to irrational irrigation systems (Wu et al.2014). The synergetic effects of natural and anthropogenic drivers further complicate conventional groundwater quality problems, where only natural factors are involved.

It is widely accepted that groundwater is closely related with human society (Scholz et al. 2000; Anderson 2014), and groundwater quality research must consider these social attributes. This further increases the complexity of the study in this field. In western China, groundwater quality research is also complicated by the area's complex ethnic relationships. Minorities make up approximately one fifth of the population in northwest China, and groundwater quality research has lagged behind eastern China. The Silk Road economic belt project may attract more people and industries in western China ( $\mathrm{Li}$ et al. 2015), further increasing the difficulty of groundwater quality research. Finally, groundwater quality research is multidisciplinary, covering natural sciences such as geology, hydrology, ecology, environmental sciences, geochemistry; and social sciences such as philosophy, sociology, and anthropology. The intricate knowledge structures and vast theoretical systems of these disciplines have also contributed to the complexity of groundwater quality research.

\section{Groundwater Quality Research is a Long-Term Task}

Societal development is a long and unpredictable process. Groundwater quality research, closely associated with social development, is also a difficult and long-term task. In fact, ever since humans emerged on the planet, the groundwater environment has been affected by their activities, and humanity will continue in the future to drive the variations in groundwater quality. In addition, the natural attributes of groundwater also dictate that groundwater quality research be a long-term process. Compared with surface water, groundwater can resist contaminants released by human activities (Davies and Mazurek 1997). However, once contaminated, groundwater pollution is more difficult to remediate (Caliman et al. 2010) and is a long-term process.

Scientific and technological developments also make groundwater quality research a long-term task, as the current science and technology is still not well developed. For example, groundwater quality-monitoring networks are not well established in many parts of western China, and those that exist have incomplete monitoring parameters and/or inadequate monitoring frequencies. Furthermore, manual monitoring is required in most western China regions because of the high price of automated monitoring devices. Some existing probes may provide unacceptable precision due to diverse field conditions.

Another example of scientific tool that has not been fully applied in groundwater quality research concerns multiwell tracer tests conducted in a radially convergent flow field (Chen et al. 2006; Moench 1989). This test method is an efficient and environmentally friendly way to simultaneously determine hydrogeological and dispersion parameters, due to its short duration and low anthropogenic pollution ( $\mathrm{Li}$ et al. 2012). However, this method is currently not widely applied because the complex theory and difficult analytical solutions. Identifying easy and efficient solutions to apply this research tool may require time.

\section{Groundwater Quality Research is Associated with Great Uncertainty}

Uncertainty is common in groundwater quality research and included in monitored data, prediction models, and 
model conceptualization and calibration (Gorokhovski 2014). For example, quantifying anthropogenic effects on groundwater quality is uncertain and requires subjective judgments. Social development is full of uncertainties, making groundwater quality research also uncertain. Uncertainties in groundwater quality research are also created by national policy making, as research is constrained by national policies and regulation. When policies change, research may also shift. The National Natural Science Foundation of China has financially supported many groundwater quality projects, driving many great achievements in the field. However, if financial support is reduced or stopped, the research may be difficult to continue.

\section{Higher Requirements to Professional and Technical Personnel}

In recent years, national and local research institutes and universities have focused on researching groundwater that has been impacted by human intervention. However, the complexity and uncertainty associated with this research requires research scientists and technical professionals to meet challenging scholarly and technical requirements. Different from traditional hydrogeological investigations, research involving human-impacted groundwater quality covers a broad research scope, requiring solid professional knowledge, a broad international perspective, and a highlevel strategic thoughtfulness. For example, groundwater quality modeling is a useful tool (Yao et al. 2015), but only a few institute and university researchers can do this modeling. Groundwater quality research relies on many new theories, technologies, and methods. Some experienced researchers have practical experience, but may lack the new knowledge required for contemporary groundwater quality research. This hinders their ability to give good instruction to the next generation of researchers.

\section{Challenges to Cooperation and Data Sharing}

Cooperation and data sharing are significant challenges in China (Li et al. 2014b). Government agencies do not currently release the monitoring data critical for model calibration and verification. Instead, these data are controlled by selected organizations, agencies, or even individuals, and are never shared. Some data may lack consistency and standardization, and some data are poorly and inaccurately recorded. These poor monitoring data cannot readily be used for scientific research. Mechanisms supporting scientific research cooperation also face significant challenges, especially in the area of international cooperation. Most studies have been conducted by a single research institute, university, or an academic organization without cooperation between them. Solving groundwater quality problems is not an individual affair; instead, it requires close cooperation among individuals, local agencies, and international organizations. Therefore, strengthening cooperation and data sharing is important to safeguard groundwater quality research.

\section{Challenges to Advanced Technologies}

As noted above, contemporary groundwater quality research relies extensively on advanced science and technology. Remote sensing, isotopic techniques, and numerical simulation are widely applied and play an important role in assessing and predicting groundwater quality, understanding groundwater quality evolution, and describing interactions between groundwater and the ecological environment. However, as human activities expand, human impacts on groundwater quality are diversifying, requiring more advanced science and techniques. Therefore, more powerful and efficient technologies must be developed, while also applying currently available methods.

\section{Paths Forward}

Advancements in groundwater quality research in western China are not going smoothly right now. As such, this section outlines several suggestions, covering topics such as groundwater policy, groundwater education, groundwater technology, and research cooperation.

1. Groundwater quality protection requires more attention from both governments and individuals. Enforcing groundwater quality protection and management laws and regulations is critical. Recently released standards and technical guidelines for groundwater quality and groundwater environmental impact assessment (Ministry of Environmental Protection of China 2016; Ministry of Land and Resources of China 2015) are a good start for protecting groundwater quality in China. In addition, more government funds are needed to support groundwater quality research projects, as research achievements are only possible with sufficient budgets. Budgets for both basic and applied research are needed, as both are crucial for advancing groundwater quality research. Furthermore, local water pricing policy and wastewater reuse are good tools for groundwater resources management and protection (Easter and Huang 2014; Robins and Fergusson 2014), benefiting both humans and the environment. However, water pricing and wastewater reuse policies are currently lacking or are imperfect in many western 
China cities. Local governments should consider establishing water pricing policies or wastewater reuse guidelines, based on specific situations.

2. Environmental education is the foundation for effective and efficient groundwater quality research in western China. Enhancing environmental education has at least three benefits for groundwater quality research. First, it would further increase groundwater quality protection awareness among residents in western China. Second, education will result in more professional scholars and workers with comprehensive knowledge of groundwater quality protection and management. These professionals are essential to advancing groundwater quality research. Third, enhanced environmental education can inspire rapid science and technology development, critical and essential for effective and efficient groundwater quality research. Currently, educational levels, including environmental education levels, in western China are behind eastern China. Therefore, I encourage local and national educational departments to further support environmental education in western China.

3. Collaboration among different national and/or international organizations is important for effective and efficient groundwater quality research in western China. Some collaboration has occurred between Chinese institutes and international organizations (Dohmann et al. 2016). However, existing international collaboration is more common in eastern China, where the economy is more prosperous. Western China, however, faces more environmental threats because of its fragile environment, intensified mining and industrial activities, and undeveloped science and technology. Hence, international collaboration is even more important and meaningful for western China.

4. Groundwater quality monitoring is effective in preventing hydrogeological system pollution (Vrba and Pěkný 1991), and monitoring data supports groundwater management plan design and groundwater resource security (Lee and Kwon 2016). However, current groundwater quality-monitoring networks in western China are imperfect, with inadequate groundwater quality-monitoring wells, irrational monitoring parameters and frequencies, undeveloped monitoring and detection techniques, and a short monitoring history (Li 2014). These problems must be solved, and groundwater quality-monitoring networks need to be improved and optimized to safeguard groundwater quality protection and research.

5. Groundwater quality data management must also be improved. Most monitoring data are not available to the public. This is the biggest barrier preventing high quality groundwater research (Nussbaumer et al. 2016). To improve the data quality and management, the following recommendations are proposed: (1) establish a uniform information management platform that can store and release standardized groundwater quality data from both local and national monitoring stations; (2) enhance the fundamental database of groundwater contamination sources, including wastewater amounts, outlet positions, contaminant characteristics, hydrogeological conditions, monitoring well information, monitoring data, and monitoring reports; (3) release monitoring results regularly and comprehensively, so that groundwater quality and information about contaminants are available for public inspection.

\section{Final Remarks}

Groundwater quality research in western China faces significant challenges due to rapid societal development and intensifying human activities. Despite this, there have been many achievements in this field over the past several decades. These successes led me to edit this special issue. I hope these latest research achievements will reach international scholars, and attract more researchers to this field.

The special issue includes ten research papers. The research paper by Wu and Sun (2015) reports on shallow groundwater pollution and associated health risks due to agricultural and industrial activities in a mid-west part of China. The authors' proposed strategies are quite helpful and practical for coping with groundwater pollution. Industries are dominant factors driving groundwater quality deterioration in western China. Studies carried out by $\mathrm{Li}$ et al. $(2016 \mathrm{~b}, \mathrm{c})$ reported that groundwater pollution was induced by industrial wastewater in the Weining Plain.

Industrial activities often produce point source pollution, while agricultural activity is the biggest source of nonpoint source pollution. In this special issue, several papers report that nitrogen pollution is solely or partially induced by agricultural activities (e.g., Wu and Sun 2015; Li et al. 2016c; Chen et al. 2016b). Different from previous studies, Jiang et al. (2016) used isotopic signatures to determine that nitrate in groundwater may also be derived from atmospheric precipitation. Further, soil column experiments show that nitrite transport in shallow sedimentary aquifers of northwest China is influenced by factors such as flow velocity, temperature, and $\mathrm{pH}$ (Dou et al. 2016a). In addition to nitrogen pollution, organic pollution is emerging rapidly in western China (e.g., Li et al. 2016b; Zeng et al. 2016). These contaminants come mainly from human activities. Therefore, these activities should be wisely regulated and more water resource management research should be conducted. Dou et al. (2016b) reported by hydrochemical and isotopic signatures of groundwater 
that elevated fluoride in groundwater can be partially attributed to agricultural activities, although natural factors such as fluorite dissolution and groundwater evaporation are the dominant influencing factors. Numerical modeling is also a powerful tool in groundwater contamination studies. In this special issue, the research by Wang et al. (2016) applied this technique to investigate and predict the possible impacts of acid mine drainage on groundwater quality. It is also interesting to notice that several papers (Wu and Sun 2015; Li et al. 2016c; Chen et al. 2016b; Zhou et al. 2016) integrated water quality assessment and health risk assessment in their studies, which is, in my opinion, a true advancement for conventional water quality assessment and should be encouraged.

The papers in this special issue are designed to help local decision makers combat groundwater contamination and reduce the health risks produced by contaminated groundwater consumption. These studies are one step toward protecting groundwater quality and establishing harmonious relationships between society and the environment ( $\mathrm{Li}$ et al. 2016c). I invite more scholars and organizations in this research field to actively advance this important work.

Acknowledgments A part of this article is edited from my $\mathrm{Ph} . \mathrm{D}$. dissertation, and I sincerely acknowledge the five anonymous reviewers and the dissertation defense committee for their constructive comments. I am also grateful for the financial supports from the Foundation of Outstanding Young Scholar of Chang'an University (310829153509), the National Natural Science Foundation of China (41502234), the Research Funds for Young Stars in Science and Technology of Shaanxi Province (2016KJXX-29), the General Financial Grant from the China Postdoctoral Science Foundation (2015M580804), the Special Financial Grant from the China Postdoctoral Science Foundation (2016T90878), the Special Financial Grant from the Shaanxi Postdoctoral Science Foundation, and the Fundamental Research Funds for the Central Universities (310829151072). This article acts as an editorial introduction to the special issue "Groundwater Quality in Western China." Sincere thanks are extended to the editorial office of Exposure and health, especially to Prof. Andrew Meharg, the Editor in Chief, and Ms Helen James, the Editorial Assistant. Without their help and support, this special issue would have never been published. Prof. Meharg handled my papers in the peer review processes. Helen acted as a bridge linking authors, editors and the publisher. The scientists who contributed to this special issue as volunteer reviewers are sincerely acknowledged for their helpful comments on the manuscripts. Contributing authors are also appreciated for their interests in this special issue and strictly adherence to the timelines.

\section{Compliance with Ethical Standards}

Conflicts of Interest The author declares no conflict of interest.

\section{References}

Anderson MP (2014) Groundwater research and management: new directions and re-invention. In: Taniguchi M, Hiyama T (eds)
Groundwater as a key for adaptation to changing climate and society. Springer, Tokyo, pp 1-15

Azizullah A, Khattak MNK, Richter P, Häder DP (2011) Water pollution in Pakistan and its impact on public health-a review. Environ Int 37(2):479-497. doi:10.1016/j.envint.2010. 10.007

Bhutiani R, Kulkarni DB, Khanna DR, Gautam A (2016) Water quality, pollution source apportionment and health risk assessment of heavy metals in groundwater of an industrial area in North India. Exposure and Health 8(1):3-18. doi:10.1007/ s12403-015-0178-2

Caliman FA, Robu BM, Smaranda C, Pavel VL, Gavrilescu M (2010) Soil and groundwater cleanup: benefits and limits of emerging technologies. Clean Techn Environ Policy 13:241-268. doi:10. 1007/s10098-010-0319-z

Chen JS, Liu CW, Liang CP (2006) Evaluation of longitudinal and transverse dispersivities/distance ratios for tracer test in a radially convergent flow field with scale-dependent dispersion. Adv Water Resour 29:887-898

Chen S, Yang W, Huo Z, Huang G (2016a) Groundwater simulation for efficient water resources management in Zhangye Oasis Northwest China. Environ Earth Sci 75:647. doi:10.1007/ s12665-016-5458-z

Chen J, Wu H, Qian H (2016b) Groundwater nitrate contamination and associated health risk for the rural communities in an agricultural area of Ningxia, northwest China. Expo Health. doi:10.1007/s12403-016-0208-8

Chidambaram S, Prasad MBK, Prasanna MV, Manivannan R, Anandhan P (2015) Evaluation of metal pollution in groundwater in the industrialized environs in and around Dindigul, Tamilnadu, India. Water Qual Expo Health 7(3):307-317. doi:10. 1007/s12403-014-0150-6

China Groundwater Information Web (2016) Groundwater pollution map. Available at http://219.142.70.139/dxs/Hydres.htm. Accessed 12 April, 2016 (in Chinese)

Davies JC, Mazurek J (1997) Regulating pollution: does the US system work. Diane Publishing, Collingdale

Dohmann M, Chen C, Grambow M, Kolditz O, Krebs P, Schmidt KR, Subklew G, Tiehm A, Wermter P, Dai XH, Liao ZL, Meng W, Song YH, Yin D, Zheng BH (2016) German contributions to the Major Water Program in China: "Innovation Cluster-Major Water". Environ Earth Sci 75:703. doi:10.1007/s12665-0165504-X

Dou Y, Howard KWF, Qian H (2016a) Transport characteristics of nitrite in a shallow sedimentary aquifer in northwest China as determined by a 12-day soil column experiment. Expo Health. doi:10.1007/s12403-016-0206-x

Dou Y, Howard K, Yang L, Wang D, Guo L (2016b) Hydrochemistry of fluoride in groundwaters from the Permo-Triassic Aquifer System of Central Shaanxi Province, Northwest China. Expo Health. doi:10.1007/s12403-016-0218-6

Easter KW, Huang Q (2014) Water markets for the 21st century: what have we learned?. Springer, Dordrecht

Gorokhovski V (2014) Effective parameters of hydrogeological models, 2nd edn. Springer International Publishing, Cham

Jiang W, Wang G, Sheng Y, Zhao D, Liu C, Guo Y (2016) Enrichment and sources of nitrogen in groundwater in the Turpan-Hami area, Northwestern China. Expo Health. doi:10. 1007/s12403-016-0209-7

Lee J-Y, Kwon KD (2016) Current status of groundwater monitoring networks in Korea. Water 8:168. doi:10.3390/w8040168

Li P (2014) Research on groundwater environment under human interferences: a case study from weining plain, Northwest China. $\mathrm{Ph} . \mathrm{D}$. Thesis, Chang' an University, Xi' an (in Chinese)

Li P (2016) Groundwater environment under human interference and the methodological system for research in this field. South-to- 
North Water Transf Water Sci Technol 14(1):18-24 (in Chinese)

Li P, Qian H, Wu J, Ding J (2012) Determination of parameters for contaminant transport through porous media in a radially convergent flow field. Int J Adv Earth Sci 1(1):33-38

Li P, Wu J, Qian H (2014a) Hydrogeochemistry and quality assessment of shallow groundwater in the southern part of the Yellow River alluvial plain (Zhongwei section), China. Earth Sci Res J 18(1):27-38. doi:10.15446/esrj.v18n1.34048

Li P, Qian H, Wu J (2014b) Accelerate research on land creation. Nature 510(7503):29-31. doi:10.1038/510029a

Li P, Qian H, Howard KWF, Wu J (2015) Building a new and sustainable "Silk Road economic belt". Environ Earth Sci 74(10):7267-7270. doi:10.1007/s12665-015-4739-2

Li P, Wu J, Qian H (2016a) Regulation of secondary soil salinization in semi-arid regions: a simulation research in the Nanshantaizi area along the Silk Road, northwest China. Environ Earth Sci 75:698. doi:10.1007/s12665-016-5381-3

Li P, Wu J, Qian H, Zhang Y, Yang N, Jing L, Yu P (2016b) Hydrogeochemical characterization of groundwater in and around a wastewater irrigated forest in the southeastern edge of the Tengger Desert Northwest China. Expo Health. doi:10. 1007/s12403-016-0193-y

Li P, Li X, Meng X, Li M, Zhang Y (2016c) Appraising groundwater quality and health risks from contamination in a semiarid region of northwest China. Expo Health. doi:10.1007/s12403-0160205-y

Mamat Z, Halik U, Muhtar P, Nurmamat I, Abliz A (2016) Temporal variation of significant soil hydrological parameters in the Yutian oasis in Northwest China from 2001 to 2010. Environ Earth Sci 75:287. doi:10.1007/s12665-015-5152-6

Ministry of Environmental Protection of China (2016) Technical guidelines for environmental impact assessment: groundwater environment, HJ 610-2016. China Environmental Science press, Beijing

Ministry of Land and Resources of China (2015) Standard for groundwater quality, DZ/T 0290-2015. Geological Publishing House, Beijing

Moench AF (1989) Convergent radial dispersion: a laplace transform solution for aquifer tracer testing. Water Resour Res 25(3):439-447

Nickson RT, McArthur JM, Shrestha B, Kyaw-Nyint TO, Lowry D (2005) Arsenic and other drinking water quality issues, Muzaffargarh District, Pakistan. Appl Geochem 20:55-68. doi:10. 1016/j.apgeochem.2004.06.004

Nussbaumer D, Sutton I, Parker A (2016) Groundwater data management by water service providers in Peri-Urban areas of Lusaka. Water 8:135. doi:10.3390/w8040135
Peng J, Qiao J, Leng Y, Wang F, Xue S (2016) Distribution and mechanism of the ground fissures in Wei River Basin, the origin of the Silk Road. Environ Earth Sci 75:718. doi:10.1007/s12665016-5527-3

Rebolledo B, Gil A, Flotats X, Sánchez JÁ (2016) Assessment of groundwater vulnerability to nitrates from agricultural sources using a GIS-compatible logic multicriteria model. J Environ Manag 171:70-80. doi:10.1016/j.jenvman.2016.01.041

Robins NS, Fergusson J (2014) Groundwater scarcity and conflictmanaging hotspots. Earth Perspect 1:6. doi:10.1186/2194-6434$1-6$

Scholz RW, Mieg HA, Oswald JE (2000) Transdisciplinarity in Groundwater Management-Towards Mutual Learning of Science and Society. Water Air Soil Pollut 123(1):477-487. doi:10.1023/A:1005292328778

Vrba J, Pĕkný V (1991) Groundwater-quality monitoring-effective method hydrogeological system pollution prevention. Environ Geol Water Sci 17(1):9-16. doi:10.1007/BF01716070

Wang JX, Huang JK, Rozelle S, Huang QQ, Blanke A (2007) Agriculture and groundwater development in northern China: trends, institutional responses, and policy options. Water Policy 9(S1):61-74. doi:10.2166/wp.2007.045

Wang W, Qiang Y, Wang Y, Sun Q, Zhang M (2016) Impacts of Yuyang Coal Mine on groundwater quality in Hongshixia water source, northwest China: a chemical and modeling research. Expo Health. doi:10.1007/s12403-016-0223-9

Wu J, Sun Z (2015) Evaluation of shallow groundwater contamination and associated human health risk in an alluvial plain impacted by agricultural and industrial activities, Mid-west China. Expo Health. doi:10.1007/s12403-015-0170-x

Wu J, Li P, Qian H, Fang Y (2014) Assessment of soil salinization based on a low-cost method and its influencing factors in a semiarid agricultural area, northwest China. Environ Earth Sci 71(8):3465-3475. doi:10.1007/s12665-013-2736-x

Xie Y, Wang G, Wang X (2015) Spatio-temporal process of oasification in the middle-Heihe River basin during 1368-1949 AD. China. Environ Earth Sci 73(4):1663-1678. doi:10.1007/ s12665-014-3519-8

Yao YY, Zheng CM, Tian Y, Liu J, Zheng Y (2015) Numerical modeling of regional groundwater flow in the Heihe River Basin, China: advances and new insights. Earth Sciences, Science China. doi:10.1007/s11430-014-5033-y

Zeng Y, Zhou J, Zhou Y, Jia R (2016) Assessment and causes of groundwater organic pollution in typical plain areas in Xinjiang, China. Expo Health. doi:10.1007/s12403-016-0211-0

Zhou Y, Wei A, Li J, Yan L, Li J (2016) Groundwater quality evaluation and health risk assessment in the Yinchuan region, northwest China. Expo Health. doi:10.1007/s12403-016-0219-5 